\title{
Matrix-isolation FTIR, theoretical structural analysis and reactivity of amino-saccharins: $N$-(1,1-dioxo-1,2-benzisothiazol-3-yl)- $N$-methyl amine and -N,N-dimethyl amine
}

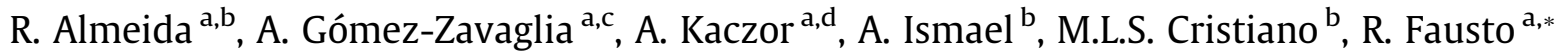 \\ ${ }^{a}$ Department of Chemistry, University of Coimbra, P-3004-535 Coimbra, Portugal \\ ${ }^{\mathrm{b}}$ CCMAR and Department of Chemistry and Pharmacy, F.C.T., University of Algarve, P-8005-039 Faro, Portugal \\ ${ }^{\mathrm{C}}$ Center for Research and Development in Food Cryotechnology (Conicet - La Plata, UNLP), RA-1900, La Plata, Argentina \\ ${ }^{\mathrm{d}}$ Faculty of Chemistry, Jagiellonian University, Ingardena 3, 30-060 Krakow, Poland
}

\section{A R T I C L E I N F O}

\section{Article history:}

Received 25 August 2009

Received in revised form 21 September 2009

Accepted 22 September 2009

Available online 26 September 2009

\section{Keywords:}

Amino-substituted benzisothiazoles

Molecular structure

Quantum chemical calculations

Matrix-isolation infrared spectroscopy

$\mathrm{C}-\mathrm{N}$ bond lengths

Reactivity

\begin{abstract}
A B S T R A C T
In this work, two novel amino-substituted derivatives of saccharin, $N$-(1,1-dioxo-1,2-benzisothiazol-3yl)- $N$-methyl amine (MBAD) and $N$-(1,1-dioxo-1,2-benzisothiazol-3-yl)- $N, N$-dimethyl amine (DMBAD), were synthesized and characterized, and their molecular structure and vibrational properties were investigated by matrix-isolation FTIR spectroscopy and theoretical calculations undertaken using different levels of approximation. The calculations predicted the existence of two conformers of MBAD. The lowest energy form was predicted to be considerably more stable than the second conformer $(\Delta E>c a$. $20 \mathrm{~kJ} \mathrm{~mol}^{-1}$ ) and was the sole form contributing to the infrared spectrum of the compound isolated in solid xenon. Both conformers have planar amine moieties. In the case of DMBAD, only one doubly-degenerated-by-symmetry conformer exists, with the amine nitrogen atom considerably pyramidalized. The effect of the electron-withdrawing saccharyl ring on the $\mathrm{C}-\mathrm{N}$ bond lengths is discussed. The different structural preferences around the amine nitrogen atom in the two molecules were explained in terms of repulsive interactions involving the additional methyl group of DMBAD. Observed structural features are correlated with the reactivity exhibited by the two compounds towards nucleophiles. The experimentally obtained spectra of the matrix-isolated monomers of MBAD and DMBAD were fully assigned by comparison with the corresponding calculated spectra.
\end{abstract}

(c) 2009 Elsevier B.V. All rights reserved.

\section{Introduction}

Saccharin (1,2-benzisothiazol-3(2H)-one-1,1-dioxide) is a commonly known substance as it is the oldest artificial sweetener and has been the subject of many studies. More recently, several saccharyl derivatives have also been attracting an increased attention, as they show herbicidal, antimicrobial and antifungal activities [1].

Benzisothiazoles are also important in synthesis. Due to the powerful electron-withdrawing properties of the saccharyl system, benzisothiazolyl ethers have been successfully used as intermediate compounds for reductive cleavage of $\mathrm{C}-\mathrm{O}$ bonds in phenols, benzyl- and naphthyl alcohols, catalysed by transition metals, using hydrogen donors [2-4]. The saccharyl system, together with the oxygen from the original phenol or alcohol, represents an efficient nucleofuge in heterogeneous catalytic transfer hydrogenoly-

\footnotetext{
* Corresponding author.

E-mail address: rfausto@ci.uc.pt (R. Fausto).
}

sis [2-4] or cross-coupling with organometallic reagents [5]. The electron-withdrawing abilities of the benzisothiazolyl system are also in keeping with the easy thermally induced sigmatropic isomerisation of 3-allyloxy- and 3-alkoxy-derivatives of benzisothiazole to the corresponding $N$-allyl or $N$-alkyl isomers [6-10].

In recent studies on this family of compounds, we investigated the structure and spectroscopic properties of simple alkyloxy- and allyloxy-derivatives [specifically, 3-(methoxy)-1,2-benzisothiazole 1,1-dioxide and 3-(allyloxy)-1,2-benzisothiazole 1,1-dioxide] and the mechanisms involved in their thermal rearrangement to the corresponding $\mathrm{N}$-alkyl or $\mathrm{N}$-allyl isomers [9-14]. In those studies, the interpretation of the experimental data strongly relied on quantum chemical theoretical calculations, which had to be first duly calibrated in order to consider the specificities of the molecular systems under analysis. One important result obtained from those studies was the conclusion that high-order polarization functions must be present in the basis sets used in the calculations for an appropriate description of the $>\mathrm{SO}_{2}($ or $\mathrm{S}=\mathrm{O})$ moiety [8]. In particular, the use of the DFT/B3LYP method with the $6-311++G(3 d f, 3 p d)$ basis set was shown to be appropriate to 
attain reliable structural and spectroscopic results at moderate computational effort when compared to other theoretical approaches suggested before [15-17].

In the present investigation we focused on two amino-substituted benzisothiazoles: $N$-(1,1-dioxo-1,2-benzisothiazol-3-yl)- $N$ methyl amine ( $N$-methyl-1,2-benzisothiazol-3-amine 1,1-dioxide; MBAD) and $N$-(1,1-dioxo-1,2-benzisothiazol-3-yl)- $N, N$-dimethyl amine (N,N-dimethyl-1,2-benzisothiazol-3-amine 1,1-dioxide; DMBAD). From a structural point of view, $\mathrm{C}-\mathrm{N}$ bonds in amines have received much less attention than $\mathrm{C}-\mathrm{O}$ bonds in ethers and alcohols [18]. In fact, due to the difference in electronegativity between nitrogen and oxygen, cleavage of a $\mathrm{C}-\mathrm{N}$ bond in aliphatic or aromatic amines, through hydrogenolysis or reaction with a nucleophile, is much more difficult than cleavage of a $\mathrm{C}-\mathrm{O}$ bond in the corresponding ethers or alcohols [19]. The saccharyl derivatives of methyl amine and dimethylamine, MBAD and DMBAD, were isolated in solid xenon and their conformational preferences and vibrational properties studied by infrared spectroscopy. Interpretation of the experimental data received support from quantum chemical calculations. Structural analysis has shown that the dimethyl-compound has a pyramidal amino nitrogen group whereas the mono-substituted compound has a planar nitrogen amino group; i.e., the $\mathrm{C}_{(\mathrm{ring})}-\mathrm{N}$ bond is considerably stronger in the mono-substituted compound than in the di-substituted one. These structural differences between the two saccharyl amines result in their different reactivity towards nucleophilic displacement by phenoxide anion.

\section{Experimental and computational methods}

MBAD and DMBAD were synthesized from reaction of pseudosaccharyl chloride (3-chloro-1,1-dioxo-1,2-benzisothiazole) with methylamine or dimethylamine, respectively:

\subsection{N-(1,1-Dioxo-1,2-benzisothiazol-3-yl)-N-methyl amine (MBAD)}

A solution of the methylamine $(5 \mathrm{mmol})$ in THF $(5 \mathrm{~mL})$ was added to a stirring solution of pseudosaccharyl chloride $(5 \mathrm{mmol}$ ) in THF $(10 \mathrm{~mL})$. The final mixture was stirred at room temperature for $6 \mathrm{~h}$, then it was made alkaline (aq. $\mathrm{NaOH}$ ). An excess of icewater was added, and the formed precipitate filtered and recrystallised to give the required amine as colourless crystals (76\% yield; m.p. $\left.306-308^{\circ} \mathrm{C}\right) .{ }^{1} \mathrm{H}$ NMR $\left(400 \mathrm{MHz}, \mathrm{CD}_{3} \mathrm{OD}\right): \delta 3.13(3 \mathrm{H}, \mathrm{s}$, $\left.-\mathrm{CH}_{3}\right), 3.30(\mathrm{~s}, \mathrm{~N}-\mathrm{H}), 7.77-7.81(2 \mathrm{H}, \mathrm{m}, \mathrm{Ar}-\mathrm{H}), 7.93-7.95(1 \mathrm{H}, \mathrm{d}$, Ar-H) MS (EI), m/z $197[\mathrm{M}+\mathrm{H}]^{+}$.

\subsection{N-(1,1-Dioxo-1,2-benzisothiazol-3-yl)-N,N-dimethyl amine (DMBAD)}

A solution of the dimethylamine $(5 \mathrm{mmol})$ in THF $(5 \mathrm{~mL})$ was added to a stirring solution of pseudosaccharyl chloride $(5 \mathrm{mmol}$ ) in THF $(10 \mathrm{~mL})$. The final mixture was stirred at $40{ }^{\circ} \mathrm{C}$ for $8 \mathrm{~h}$, then it was made alkaline (aq. $\mathrm{NaOH}$ ). An excess of ice-water was added, and the formed precipitate filtered and recrystallised to give the required amine as colourless crystals (69\% yield; m.p. 301-

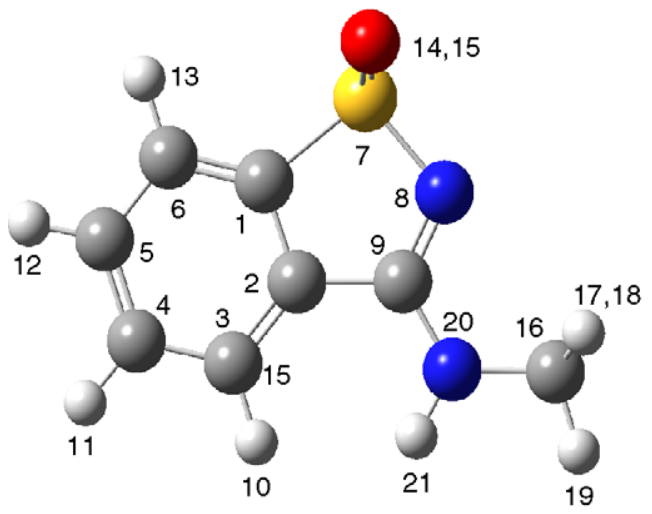

MBAD - A

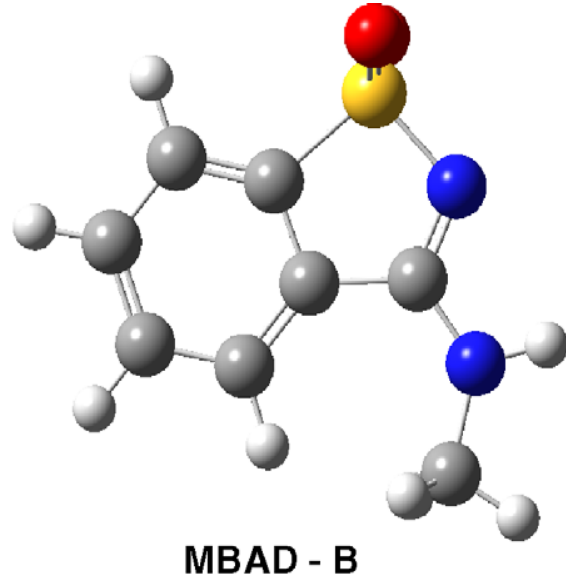

14,15

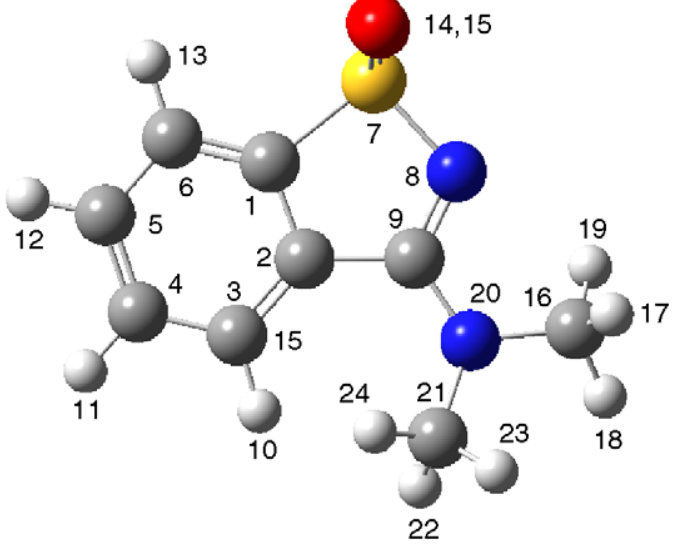

DMBAD

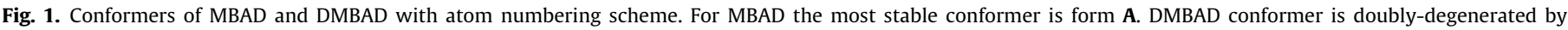
symmetry; only one of the structures is shown in the picture, the second one being the mirror image of that. 
Table 1

Zero-point corrected energies (absolute energies: $E^{\circ} /$ hartree; relative energies: $\Delta E^{\circ} / \mathrm{kJ} \mathrm{mol}^{-1}$ ) for MBAD conformers calculated at different levels of theory.

\begin{tabular}{|c|c|c|c|}
\hline \multirow[t]{2}{*}{ Method } & \multicolumn{2}{|l|}{$E^{\circ} /$ hartree } & \multirow{2}{*}{$\begin{array}{l}\Delta E^{\circ} / \mathrm{kJ} \mathrm{mol}^{-1} \\
(\mathrm{~B}-\mathrm{A})\end{array}$} \\
\hline & Conformer A & Conformer B & \\
\hline $\mathrm{HF} / 3-21 \mathrm{G}$ & -958.2408090 & -958.2319900 & 23.2 \\
\hline $\mathrm{HF} / 3-21 \mathrm{G}(\mathrm{d})$ & -958.5180230 & -958.5101410 & 20.7 \\
\hline $\mathrm{HF} / 6-31 \mathrm{G}(\mathrm{d})$ & -963.4914230 & -963.4829540 & 22.2 \\
\hline $\mathrm{HF} / 6-311++\mathrm{G}(\mathrm{d}, \mathrm{p})$ & -963.6502360 & -963.6410550 & 24.1 \\
\hline MP2/3-21G & -959.4924960 & -959.4834040 & 23.9 \\
\hline $\mathrm{MP} 2 / 3-21 \mathrm{G}(\mathrm{d})$ & -959.8122460 & -959.8046250 & 20.0 \\
\hline $\mathrm{MP} 2 / 6-311++\mathrm{G}(\mathrm{d}, \mathrm{p})$ & -965.6596330 & -965.6509790 & 22.7 \\
\hline B3LYP/3-21G & -962.3617720 & -962.3531470 & 22.6 \\
\hline B3LYP/3-21G(d) & -962.6115320 & -962.6042050 & 19.2 \\
\hline B3LYP/6-31G(d) & -967.5817510 & -967.5744400 & 19.2 \\
\hline B3LYP/6-311++G(d,p) & -967.7660880 & -967.7576650 & 22.1 \\
\hline B3LYP/6-311++G(3df,3pd) & -967.8631650 & -967.8552750 & 20.7 \\
\hline SVWN/6-311++G(d,p) & -963.6894140 & -963.6823560 & 18.6 \\
\hline SVWN/6-311++G(3df,3pd) & -963.7906950 & -963.7838590 & 18.0 \\
\hline BHandHLYP/6-311++G(d,p) & -967.3985990 & -967.3900560 & 22.4 \\
\hline BHandHLYP/6-311++G(3df,3pd) & -967.5046910 & -967.4965880 & 21.3 \\
\hline B3PW91/6-311++G(d,p) & -967.4937770 & -967.4853760 & 22.1 \\
\hline В3PW91/6-311++G(3df,3pd) & -967.5908690 & -967.5829590 & 20.8 \\
\hline B3P86/6-311++G(d,p) & -969.6099830 & -969.6017830 & 21.5 \\
\hline B3P86/6-311++G(3df,3pd) & -969.7077850 & -969.7000940 & 20.2 \\
\hline
\end{tabular}

$\left.303^{\circ} \mathrm{C}\right) .{ }^{1} \mathrm{H}$ NMR $\left(400 \mathrm{MHz}, \mathrm{CD}_{3} \mathrm{OD}\right): \delta 2.80\left(6 \mathrm{H}, \mathrm{s},-\mathrm{CH}_{3}\right), 7.77-7.81$

$(2 \mathrm{H}, \mathrm{m}, \mathrm{Ar}-\mathrm{H}), 7.93-7.95(1 \mathrm{H}, \mathrm{d}, \mathrm{Ar}-\mathrm{H}) \mathrm{MS}(\mathrm{EI}), \mathrm{m} / \mathrm{z} 211[\mathrm{M}+\mathrm{H}]^{+}$.

\subsection{Reaction of $N$-(1,1-dioxo-1,2-benzisothiazol-3-yl)- $N$-methyl amine (MBAD) with phenoxide}

Sodium hydride (95\%; $0.012 \mathrm{~g} ; 0.5 \mathrm{mmol}$ ) was added to a solution of phenol $(0.028 \mathrm{~g} ; 0.3 \mathrm{mmol})$ in dry THF $(2 \mathrm{ml})$ under anhydrous conditions. The mixture was stirred vigorously at room temperature, until effervescence had ceased (30 min). $N$-(1,1-Dioxo-1,2-benzisothiazol-3-yl)- $N$-methyl amine (MBAD) $(0.05 \mathrm{~g} ; 0.3 \mathrm{mmol})$ in dry THF $(8 \mathrm{~mL})$ was then added, and the final reaction mixture was stirred at room temperature. The progress of the reaction was controled by TLC, using toluene/acetone (5:3) as eluent. After $4 \mathrm{~h}$ the presence of a reaction product, identified as 3-phenoxy-1,2-benzisothiazole 1,1-dioxide was detected, but most of the starting material was still present. The mixture was kept stirring for another $18 \mathrm{~h}$, but no change in the extent of conversion was observed.

The reaction was repeated, but increasing the reaction temperature to $40^{\circ} \mathrm{C}$. Under these conditions, the extent of conversion had only slightly increased, after $20 \mathrm{~h}$.

\subsection{Reaction of N-(1,1-dioxo-1,2-benzisothiazol-3-yl)-N,N-dimethyl amine (DMBAD) with phenoxide}

The reaction conditions described above for MBAD were applied to DMBAD. The reaction mixture was stirred at room temperature for $20 \mathrm{~h}$. TLC analysis demonstrated that, after this period, all starting material had been converted into 3-phenoxy-1,2-benzisothiazole 1,1-dioxide. Extraction with ethyl acetate, evaporation to dryness under reduced pressure, then recrystallisation of the solid residue from ethyl acetate/DCM gave colourless crystals m.p. 102$103{ }^{\circ} \mathrm{C} .{ }^{1} \mathrm{H}$ NMR $\left(400 \mathrm{MHz}, \mathrm{CD}_{3} \mathrm{OD}\right): \delta_{\mathrm{H}}\left(\mathrm{CDCl}_{3}\right): \delta 7.31-7.42(3 \mathrm{H}$, $3 \mathrm{t}), 7.43-7.47(1 \mathrm{H}, \mathrm{d}), 7.48-7.51(1 \mathrm{H}, \mathrm{d}), 7.78-7.85(2 \mathrm{H}, \mathrm{m})$, 7.90-8.10 (2H, m); MS (EI, m/z) $260\left(\mathrm{M}^{+}\right)$.

\subsection{Matrix-isolation FTIR spectroscopy}

Matrices were prepared by co-deposition, onto the cooled CsI substrate of the cryostat, of the matrix gas (xenon 99.995\%, obtained from Air Liquide) and vapors of the compound under study produced by evaporation in a specially designed temperature variable minioven assembled inside the cryostat. The temperature of the mini- oven used for evaporation of the compounds was $448 \mathrm{~K}$ and the gas flow rates and deposition times were ca. $200 \mathrm{mbar} \mathrm{h}^{-1}$ and $\sim 1 \mathrm{~h}$, respectively, in all experiments. Though with this set up the matrix concentration cannot be measured precisely, from spectra absolute intensities we estimate it was, in all experiments, about 1:800 to 1:1000 (S:M). All low temperature experiments were done on the basis of an APD Cryogenics close-cycle helium refrigeration system with a DE-202A expander. The temperature of the CsI substrate during deposition was $20 \mathrm{~K}$. The IR spectra were collected, with $0.5 \mathrm{~cm}^{-1}$ spectral resolution, on a Mattson (Infinity 60AR Series) Fourier Transform infrared spectrometer, equipped with a deuterated triglycine sulphate (DTGS) detector and a $\mathrm{Ge} / \mathrm{KBr}$ beamsplitter.

\subsection{Computational details}

Calculations were performed at several levels of approximation using the Gaussian03 suite of programs and the default algorithms it implements [20]. In some cases, the Geometry Direct Inversion of the Invariant Subspace (GDIIS) method [21,22] was used for geometry optimization. Potential energy profiles for internal rotation were calculated performing relaxed scans on the potential energy surface of the molecule along the relevant coordinates. Vibrational frequencies were calculated at each level of theory used and the nature of the stationary points resulting from optimization determined by inspection of the corresponding calculated Hessian matrix.

Characterization of the vibrational modes was made in terms of natural internal coordinates [23] using the Gar2ped [24] program.

\section{Results and discussion}

\subsection{Molecular structures and energies}

MBAD has two internal rotation axes, defined around the $\mathrm{C}_{9}-$ $\mathrm{N}_{20}$ and $\mathrm{N}_{20}-\mathrm{C}_{16}$ bonds, which in principle can give rise to conformational isomers. According to the calculations, ${ }^{1}$ two conformers

\footnotetext{
1 Calculations were performed at the following levels of theory: $\mathrm{HF} / 3-21 \mathrm{G}, \mathrm{HF} / 3-$ $21 G(d), H F / 6-31 G(d), H F / 6-311++G(d, p), M P 2 / 3-21 G, M P 2 / 3-21 G(d), M P 2 / 6$ $311++G(d, p), B 3 L Y P / 3-21 G, B 3 L Y P / 3-21 G(d), B 3 L Y P / 6-31 G(d), B 3 L Y P / 6-311++G(d, p)$ B3LYP/6-311++G(3df,3pd), SVWN/6-311++G(d,p), SVWN/6-311++G(3df,3pd), BHandHLYP/6-311++G(d,p), BHandHLYP/6-311++G(3df,3pd), B3PW91/6$311++G(d, p)$, B3PW91/6-311++G(3df,3pd), B3P86/6-311++G(d,p), B3P86/6$311++G(3 d f, 3 p d)$. The results obtained at the different levels of theory depicted no substantial differences regarding the optimized geometries.
} 
were found on the potential energy surface of the molecule, both conformers belonging to the $C_{\mathrm{s}}$ symmetry point group and exhibiting a planar amine group, with one of the methyl hydrogens eclipsing the amine hydrogen atom (Fig. 1). In the most stable conformer (A), the methyl group is oriented towards the nitrogen atom of the heterocycle $\left(\mathrm{N}_{8}=\mathrm{C}_{9}-\mathrm{N}_{20}-\mathrm{C}_{16}: 0^{\circ}\right)$, while in the less stable conformer (B) it is oriented towards the phenyl ring $\left(\mathrm{N}_{8}=\mathrm{C}_{9}-\mathrm{N}_{20}-\mathrm{C}_{16}: 180^{\circ}\right)$. The calculated structural parameters for conformer $\mathbf{A}$, obtained at the DFT(B3P86)/6-311++G(3df,3pd) level of theory are provided in Table S1 (Supplementary material).

The calculations predicted conformer A to be $c a .20 \mathrm{~kJ} \mathrm{~mol}^{-1}$ more stable than conformer $\mathbf{B}$ (Table 1). The greater stability of conformer $\mathbf{A}$ can be ascribed essentially to the more favorable interactions of the methyl and $\mathrm{NH}$ groups of the amine substituent occurring in this conformer with the $\mathrm{N}(8)$ and $\mathrm{H}(10)$ atoms, respectively (see Fig. 1). Note that in conformer $\mathbf{B}$ the planarity of the amine moiety can still be retained in spite of the repulsive interaction between the methyl group and $\mathrm{H}(10)$, because the $\mathrm{C}(2)-\mathrm{C}(9)-$ $\mathrm{N}(20)$ and $\mathrm{C}(9)-\mathrm{N}(20)-\mathrm{C}(16)$ angles can increase considerably at expenses of approaching the amine hydrogen to $\mathrm{N}(8)$. As described below, the situation is completely different for DMBAD, where the amine hydrogen is replaced by a more voluminous methyl group.

The potential energy profile for interconversion between the two MBAD conformers is presented in Fig. 2A. The energy barrier for this process is very large ( $c a .90 \mathrm{~kJ} \mathrm{~mol}^{-1}$ above the conformational ground state), in agreement with the expected considerable partial double bond character of the $\mathrm{C}(9)-\mathrm{N}(20)$ bond, which is also reflected in the planarity assumed by the amine group in both minima. On the other hand, in the transition state the amine group is considerably pyramidalized $\left(\mathrm{C}-\mathrm{N}(-\mathrm{H})-\mathrm{C}\right.$ dihedral: $\left.148.3^{\circ}\right)$, indicating a strong reduction of delocalization and of the double bond character of the $\mathrm{C}(9)-\mathrm{N}(20)$ bond, with the consequent increase of the energy of the molecule.

The presence in the DMBAD molecule of the additional methyl group leads to a completely different picture. In this case, the conformation equivalent to the minimum energy structures in MBAD is destabilized due to the repulsive interaction between one of the methyl groups and $\mathrm{H}(10)$, which cannot be minimized by opening of the $\mathrm{C}(2)-\mathrm{C}(9)-\mathrm{N}(20)$ and $\mathrm{C}(9)-\mathrm{N}(20)-\mathrm{C}(21)$ angles as in conformer $\mathbf{B}$ of MBAD because in DMBAD this would lead to unfavorable interactions between the second methyl group and $\mathrm{N}(8)$ (see Fig. 1). Hence, the amine group is forced to become pyramidal to minimize $\mathrm{CH}_{3} \ldots \mathrm{H}(10)$ repulsions. Indeed, the potential energy surface of DMBAD exhibits two symmetry equivalent minima, corresponding to structures where the dimethylamine group is non-planar $\left(\mathrm{C}-\mathrm{N}(-\mathrm{C})-\mathrm{C}\right.$ dihedral: $\left.167.3^{\circ}\right)$, with one of the methyl groups nearly in the syn periplanar position relatively to $\mathrm{N}(8)$ and the second methyl group out of the plane of the rings $[C(21)-$ $\mathrm{N}(20)-\mathrm{C}(9)-\mathrm{C}(2)$ dihedral: $\left.20.2^{\circ}\right]$. The calculated structural parameters for the sole doubly-degenerated-by-symmetry conformer of DMBAD, obtained at the DFT(B3P86)/6$311++G(3 d f, 3 p d)$ level of theory, are provided in Table S2 (Supplementary material).

The potential energy profile for internal rotation around the $\mathrm{C}(9)-\mathrm{N}(20)$ bond of DMBAD is given in Fig. 2B. All structures obtained after optimization but the transition states were of $C_{1}$ symmetry, with a pyramidalized amino group. The transition states are of $C_{\mathrm{s}}$ symmetry and correspond to the conformations where the lone electron pair of $\mathrm{N}(20)$ (defined as localized in a plane bisecting the $\mathrm{N}(8)=\mathrm{C}(9)-\mathrm{N}(20)-\mathrm{C}(16)$ and $\mathrm{N}(8)=\mathrm{C}(9)-\mathrm{N}(20)-\mathrm{C}(21)$ planes $)$ stays in the molecular plane. When $\mathrm{N}(8)=\mathrm{C}(9)-\mathrm{N}(20)$-Lp is $180^{\circ}$, the energy barrier for internal rotation is of $c a .50 \mathrm{~kJ} \mathrm{~mol}^{-1}$, whereas when $\mathrm{N}(8)=\mathrm{C}(9)-\mathrm{N}(20)$-Lp is $0^{\circ}$ the barrier is considerably higher ( $\mathrm{ca} .70 \mathrm{~kJ} \mathrm{~mol}^{-1}$ ), since for this geometry the pairs of electrons of $\mathrm{N}(20)$ and $\mathrm{N}(8)$ are face-to-face and the two methyl groups in close contact to $\mathrm{H}(10)$.
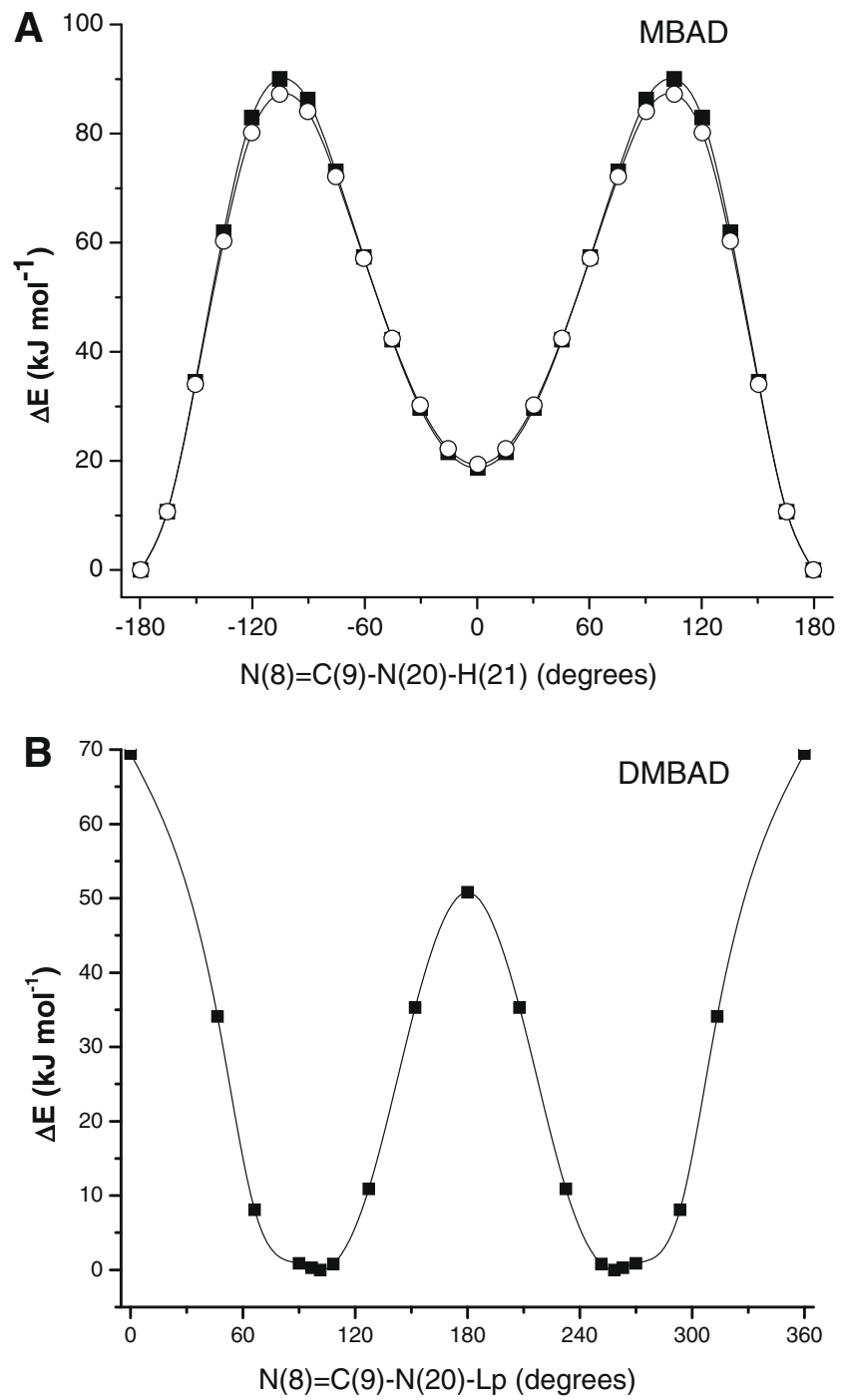

Fig. 2. (A) Potential energy profile for internal rotation around the $N(8)=C(9)-$ $\mathrm{N}(20)-\mathrm{H}(21)$ dihedral angle for MBAD. Calculations were performed at the B3P86/ $6-311++\mathrm{G}(3 \mathrm{df}, 3 \mathrm{pd})$ (black squares) and B3LYP/6-311++G(3df,3pd) (white circles) levels of theory. (B) Potential energy profile for internal rotation around the $\mathrm{N}(8)=\mathrm{C}(9)-\mathrm{N}(20)$-Lp dihedral angle ( $\mathrm{Lp}=$ lone pair, defined as localized in a plane bisecting the $\mathrm{N}(8)=\mathrm{C}(9)-\mathrm{N}(20)-\mathrm{C}(16)$ and $\mathrm{N}(8)=\mathrm{C}(9)-\mathrm{N}(20)-\mathrm{C}(21)$ planes) for DMBAD, calculated at the B3P86/6-311++G(3df,3pd) level of theory.

It is important to note once again that the main structural implications of the presence of the second methyl substituent at the amino group (in DMBAD) in relation to the mono-substituted compound (MBAD) are triggered by $\mathrm{CH}_{3} \ldots \mathrm{H}(10)$ repulsions, which lead to amine pyramidalization and reduction of the double bond character of the $C(9)-\mathrm{N}(20)$ bond. Accordingly, the $C(9)-N(20)$ bond length in DMBAD is predicted by the calculations to be $0.9 \mathrm{pm}$ longer than in MBAD (134.3 vs. $133.4 \mathrm{pm}$; see Tables S1 and S2). This effect extends into the $\mathrm{N}(8)-\mathrm{C}(9)$ bond, which is predicted to be $0.6 \mathrm{pm}$ longer in DMBAD than in MBAD (130.2 vs. $129.6 \mathrm{pm})$, and also into the $\mathrm{C}(16)-\mathrm{N}(20)$ bond, with predicted bond lengths of 145.1 and $144.5 \mathrm{pm}$, for DMBAD and MBAD, respectively.

The values predicted for bond lengths $\mathrm{C}(9)-\mathrm{N}(20)$ and $\mathrm{C}(16)-$ $\mathrm{N}(20)$ in both benzisothiazolyl derivatives correspond to bond orders greater than unity. The powerful electron-withdrawing effect of the saccharyl ring results in an increase in electronegativity on the amino nitrogen $\mathrm{N}(20)$, which is strongly conjugated with the saccharyl system. These theoretical results are in keeping with 


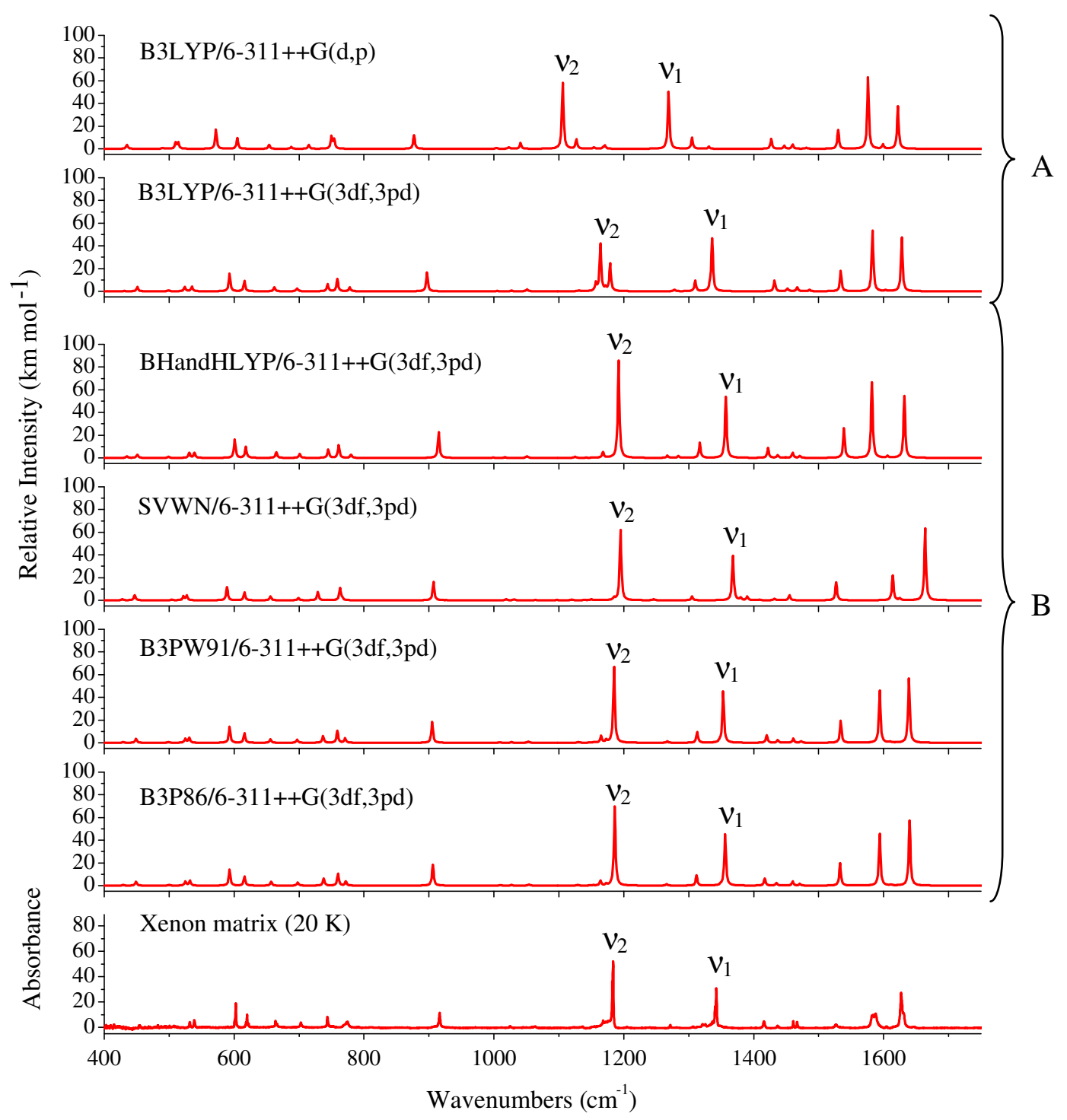

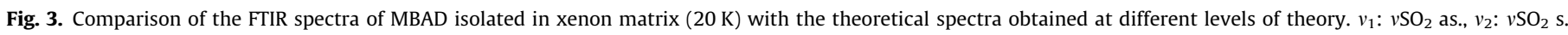
Group A depicts differences obtained with the use of polarization functions. Group B depicts differences observed using different basis sets.

those obtained from solid state analysis by X-ray crystallography performed on $\mathrm{N}$-(1,1-dioxo-1,2-benzisothiazol-3-yl)- $N$-ethylamine [25]. For this compound, the corresponding $\mathrm{C}_{(\mathrm{alkyl})}-\mathrm{N}$ and $\mathrm{C}_{\text {(saccharyl) }}-\mathrm{N}$ bond lengths are 146.0 and $132.0 \mathrm{pm}$, respectively. The structure of saccharyl derivatives of aniline has also been studied by X-ray crystallography, and the structural data correlated with the reactivity of the compounds towards catalytic transfer hydrogenolysis [25]. Results have shown that, in sharp contrast with aryl saccharyl ethers, saccharyl anilines are mostly inert to catalytic transfer hydrogenolysis. Surprisingly, when bissaccharyl anilines were subjected to hydrogenation or hydride reduction, $\mathrm{C}_{(\text {saccharyl) }}-\mathrm{N}$ cleavage was observed. Thus, unlike for saccharyl ethers, where reductive cleavage occurs selectively, under mild conditions, on the weaker $\mathrm{C}-\mathrm{O}$ bond, saccharyl anilines are inert in similar reaction conditions. However, with disaccharyl anilines, ipso replacement is observed on the saccharyl carbon, leading to cleavage of the stronger $\mathrm{C}-\mathrm{O}$ bond, if harder reaction conditions are used [25].

In the present work a comparative study of the reactivity of MBAD and DMBAD towards nucleophilic substitution was carried out. Both compounds were reacted, using similar reaction condi- tions, with phenoxide anion, generated through reaction of sodium hydride with phenol, in anhydrous conditions. Results have shown that nucleophilic displacement occurs much more easily with DMBAD than with the less hindered MBAD. These results are in agreement with the relative values calculated for the $\mathrm{C}(9)-\mathrm{N}(20)$ bond lengths and bond strengths for both compounds. Since in MBAD the $C(9)-N(20)$ bond is stronger than in DMBAD, nucleophilic displacement at $C(9)$ is easier to achieve in DMBAD than in MBAD (nucleophilic susceptibility at $\mathrm{C}(9)$ is stronger in DMBAD than in MBAD). In addition, considering that phenoxide is a considerably bulky nucleophile, it could be expected that nucleophilic approach would be easier on the planar MBAD. Though the mechanistic nature of this ipso replacement has not been investigated, considering the bulkiness of the nucleophile and the structures of both substrates, a unimolecular mechanism seems to be operating.

\subsection{Infrared spectra}

Fig. 3 depicts the infrared spectra of MBAD isolated in a Xe matrix at $20 \mathrm{~K}$ and calculated infrared spectra obtained at different 
Table 2

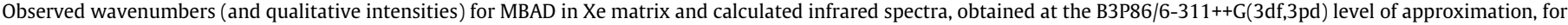
the experimentally relevant conformer of the molecule (conformer $\mathrm{A}$ ).

\begin{tabular}{|c|c|c|c|c|}
\hline \multirow[t]{2}{*}{ Approximate description ${ }^{a}$} & \multicolumn{2}{|c|}{ Calculated $^{\mathrm{b}}$ B3P86/6-311++G(3df,3pd) } & \multicolumn{2}{|c|}{ Xenon matrix ${ }^{\mathrm{c}}(20 \mathrm{~K})$} \\
\hline & $v / \mathrm{cm}^{-1}$ & $I / \mathrm{km} \mathrm{mol}^{-1}$ & $v / \mathrm{cm}^{-1}$ & $I$ (qualitative) \\
\hline$\delta \mathrm{SO}_{2}$ & 525 & 17.8 & 531 & $\mathrm{~m}$ \\
\hline$\gamma \mathrm{SO}_{2}, \tau_{6 \mathrm{R}}$ & 531 & 20.0 & 539 & $\mathrm{~m}$ \\
\hline$\delta_{5 \mathrm{R}}, \delta \mathrm{C}-\mathrm{C}-\mathrm{C}_{6 \mathrm{R}}$ & 593 & 66.4 & 603 & S \\
\hline$\delta \mathrm{C}-\mathrm{C}-\mathrm{C}_{6 \mathrm{R}}, \delta \mathrm{SO}_{2}$ & 615 & 38.8 & $620 / 623$ & $\mathrm{~S} / \mathrm{m}$ \\
\hline$\tau_{6 \mathrm{R}}, \gamma N \mathrm{H}, \delta \mathrm{N}-\mathrm{C}-\mathrm{N}$ & 657 & 15.9 & $664 / 666$ & $\mathrm{~m} / \mathrm{m}$ \\
\hline$\delta \mathrm{C}-\mathrm{C}-\mathrm{C}_{6 \mathrm{R}}, v \mathrm{C}-\mathrm{S}$ & 697 & 12.8 & 703 & $\mathrm{~m}$ \\
\hline$\tau_{6 \mathrm{R}}$ & 737 & 29.5 & 744 & $\mathrm{~m}$ \\
\hline$\delta \mathrm{C}-\mathrm{C}-\mathrm{C}_{6 \mathrm{R}}$ & 759 & 50.3 & 771 & w \\
\hline$\delta \mathrm{N}-\mathrm{C}-\mathrm{N}, \tau_{6 \mathrm{R}}$ & 771 & 17.1 & 775 & $\mathrm{~S}$ \\
\hline$\gamma \mathrm{C}-\mathrm{H}_{6 \mathrm{R}}$ & 867 & 0.0 & 909 & vw \\
\hline$v \mathrm{~N}-\mathrm{S}, \delta \mathrm{N}-\mathrm{C}-\mathrm{N}$ & 906 & 87.1 & 917 & S \\
\hline$\gamma \mathrm{C}-\mathrm{H}_{6 \mathrm{R}}$ & 947 & 0.4 & 943 & vw \\
\hline$\gamma \mathrm{C}-\mathrm{H}_{6 \mathrm{R}}$ & 986 & 0.0 & n.obs. & \\
\hline$v \mathrm{~N}-\mathrm{C}_{\mathrm{M}}, \delta \mathrm{C}-\mathrm{C}-\mathrm{C}_{6 \mathrm{R}}$ & 1010 & 1.8 & n.obs. & \\
\hline$v \mathrm{C}-\mathrm{C}_{6 \mathrm{R}}$ & 1027 & 2.5 & 1025 & w \\
\hline$\delta \mathrm{C}-\mathrm{C}-\mathrm{C}_{6 \mathrm{R}}, v \mathrm{~N}-\mathrm{C}_{\mathrm{M}}, v \mathrm{C}-\mathrm{S}$ & 1054 & 5.1 & 1064 & w \\
\hline$\gamma \mathrm{C}-\mathrm{H}_{6 \mathrm{R}}$ & 1122 & 0.2 & n.obs. & \\
\hline$\delta \mathrm{C}-\mathrm{C}-\mathrm{C}_{6 \mathrm{R}}, v \mathrm{C}-\mathrm{C}_{6 \mathrm{R}}$ & 1129 & 2.6 & 1137 & vw \\
\hline$\gamma \mathrm{CH}_{3}$ & 1153 & 1.9 & 1154 & vw \\
\hline$\gamma \mathrm{CH}_{3}$ & 1164 & 20.0 & 1168 & $\mathrm{~m}$ \\
\hline$\delta \mathrm{C}-\mathrm{C}-\mathrm{C}_{6 \mathrm{R}}, v \mathrm{C}-\mathrm{C}_{6 \mathrm{R}}$ & 1173 & 6.2 & 1173 & $\mathrm{~m}$ \\
\hline$v \mathrm{SO}_{2} \mathrm{~S}$ & 1186 & 328.9 & $1176 / 1184$ & $\mathrm{~m} / \mathrm{VS}$ \\
\hline$\delta \mathrm{C}-\mathrm{H}_{6 \mathrm{R}}$ & 1266 & 5.6 & 1271 & w \\
\hline$\delta \mathrm{NH}, v \mathrm{C}-\mathrm{C}_{5 \mathrm{R}}$ & 1312 & 42.7 & 1307 & $\mathrm{w} / \mathrm{m}$ \\
\hline$\delta \mathrm{C}-\mathrm{H}_{6 \mathrm{R}}$ & 1349 & 3.8 & 1337 & vw \\
\hline$v \mathrm{SO}_{2}$ as & 1356 & 213.8 & $1341 / 1343$ & S/VS \\
\hline$\delta \mathrm{CH}_{3} \mathrm{~S}$ & 1417 & 29.4 & 1416 & $\mathrm{~m}$ \\
\hline$\delta \mathrm{CH}_{3}$ as & 1435 & 11.9 & 1437 & $\mathrm{~m}$ \\
\hline$\delta \mathrm{C}-\mathrm{H}_{6 \mathrm{R}}, v \mathrm{C}=\mathrm{C}_{6 \mathrm{R}}$ & 1450 & 0.8 & n.obs. & w \\
\hline$\delta \mathrm{C}-\mathrm{H}_{6 \mathrm{R}}, v \mathrm{C}=\mathrm{C}_{6 \mathrm{R}}$ & 1460 & 17.2 & 1461 & w \\
\hline$\delta \mathrm{CH}_{3}$ as & 1471 & 7.0 & 1467 & $\mathrm{vw} / \mathrm{w}$ \\
\hline$v \mathrm{C}-\mathrm{N}, \delta \mathrm{N}-\mathrm{H}$ & 1533 & 92.7 & 1527 & $\mathrm{w}$ \\
\hline$v \mathrm{C}=\mathrm{C}_{6 \mathrm{R}}, v \mathrm{C}=\mathrm{N}_{5 \mathrm{R}}$ & 1594 & 214.9 & $1584 / 1588$ & $\mathrm{~S}$ \\
\hline$v \mathrm{C}=\mathrm{C}_{6 \mathrm{R}}$ & 1611 & 2.8 & $1604 / 1611$ & vw/vw \\
\hline$v \mathrm{C}=\mathrm{N}_{5 \mathrm{R}}$ & 1640 & 269.8 & $1627 / 1631$ & VS/S \\
\hline
\end{tabular}

a $v$, bond stretching; $\delta$, bending; $\gamma$, rocking; $\tau$, torsion; s, symmetric; as, anti-symmetric; subscripts $6 \mathrm{R}$, 5R and M designate the six- and the five-membered rings and the methyl group, respectively.

b Wavenumbers were scaled by 0.9763 .

c S, strong; VS, very strong; m, medium; w, weak; vw, very weak; sh, shoulder; n. obs., non observed; n.a., non-analyzed.

levels of approximation for the experimentally relevant conformer (form A). As expected, the overall agreement between theoretical and observed spectra is generally improved by increasing the number of polarization functions [e.g., from B3LYP $/ 6-311++G(d, p)$ to B3LYP/6-311++G(3df,3pd); panel A in the figure], this being particularly evident for vibrational modes of the $\mathrm{SO}_{2}$ group, such as the $v \mathrm{SO}_{2}$ anti-symmetric and symmetric stretching modes (respectively, $v_{1}$ and $v_{2}$ in Fig. 3 ), but also for $\mathrm{C}=\mathrm{C}$ stretching modes, around $1600 \mathrm{~cm}^{-1}$. Indeed, as mentioned in Section 1, the B3LYP functional used with the $6-311++\mathrm{G}(3 \mathrm{df}, 3 \mathrm{pd})$ basis set could in fact be expected to yield a good reproduction of the experimental spectrum. Nevertheless, in spite of the good performance of the B3LYP functional, the B3P86/6-311++G(3df,3pd) and B3PW91/6$311++G(3 d f, 3 p d)$ calculations were found to be those giving the best overall agreement with the experiment (panel B in Fig. 3), thus appearing as good alternatives to B3LYP/6-311++G(3df,3pd) for calculation of vibrational data on saccharin derivatives (and other molecules containing the $\mathrm{SO}_{2}$ group). For MBAD, actually both B3P86 and B3PW91 give indeed very similar results, the maximal percentage error for the wavenumbers of the bands in the fingerprint region (these taken into account in Table 2) being $0.18 \%$ and $0.23 \%$, respectively. The average percentage error for these wavenumbers is $0.02 \%$ and $0.01 \%$, respectively. On the other hand, B3LYP with the same basis set (all the time we talk about 6$311++\mathrm{G}(3 \mathrm{df}, 3 \mathrm{pd})$ ) gives considerably less good results, the maximal percentage error being $1.49 \%$ and the average percentage error
$0.16 \%$, i.e., one order of magnitude bigger than those obtained with both the B3P86 and B3PW91 functionals.

Taking into account the excellent reproduction of the experimental spectra by these calculations, the assignment of the observed bands for the matrix isolated molecule of MBAD was considerably simplified. The proposed assignments are provided in Table 2. Note that doublets of bands were assigned to most of the vibrations predicted to give rise to intense infrared bands sites (e.g., $v \mathrm{SO}_{2}$ as.: $1176 / 1184 \mathrm{~cm}^{-1} ; v \mathrm{SO}_{2}$ as.: $1341 / 1343 \mathrm{~cm}^{-1}$ ). This observation points to the existence of two main matrix sites for MBAD in xenon matrix. Annealing experiments revealed no spectral changes which could be ascribed to other phenomena than aggregation, which started to be important above ca. $40 \mathrm{~K}$.

The infrared spectrum of DMBAD isolated in xenon matrix is shown in Fig. 4, together with calculated spectra for this compound. Like for MBAD, the correspondence between the B3P86/6-311++G(3df,3pd) theoretically predicted spectrum and the experiment is very good and strongly supports the theoretical predictions regarding the structure of the stable conformation of this molecule. In particular, in consonance with the structural results, the frequency of the stronger $\mathrm{C}(9)-\mathrm{N}(20)$ bond in MBAD $\left(1527 \mathrm{~cm}^{-1}\right)$ is considerably larger than that observed for DMBAD $\left(1432 \mathrm{~cm}^{-1}\right)$. The complete assignments for DMBAD are given in Table 3. As for MBAD, matrix site splitting was also observed in case of DMBAD, with at least three main matrix sites appearing to be significantly populated. 


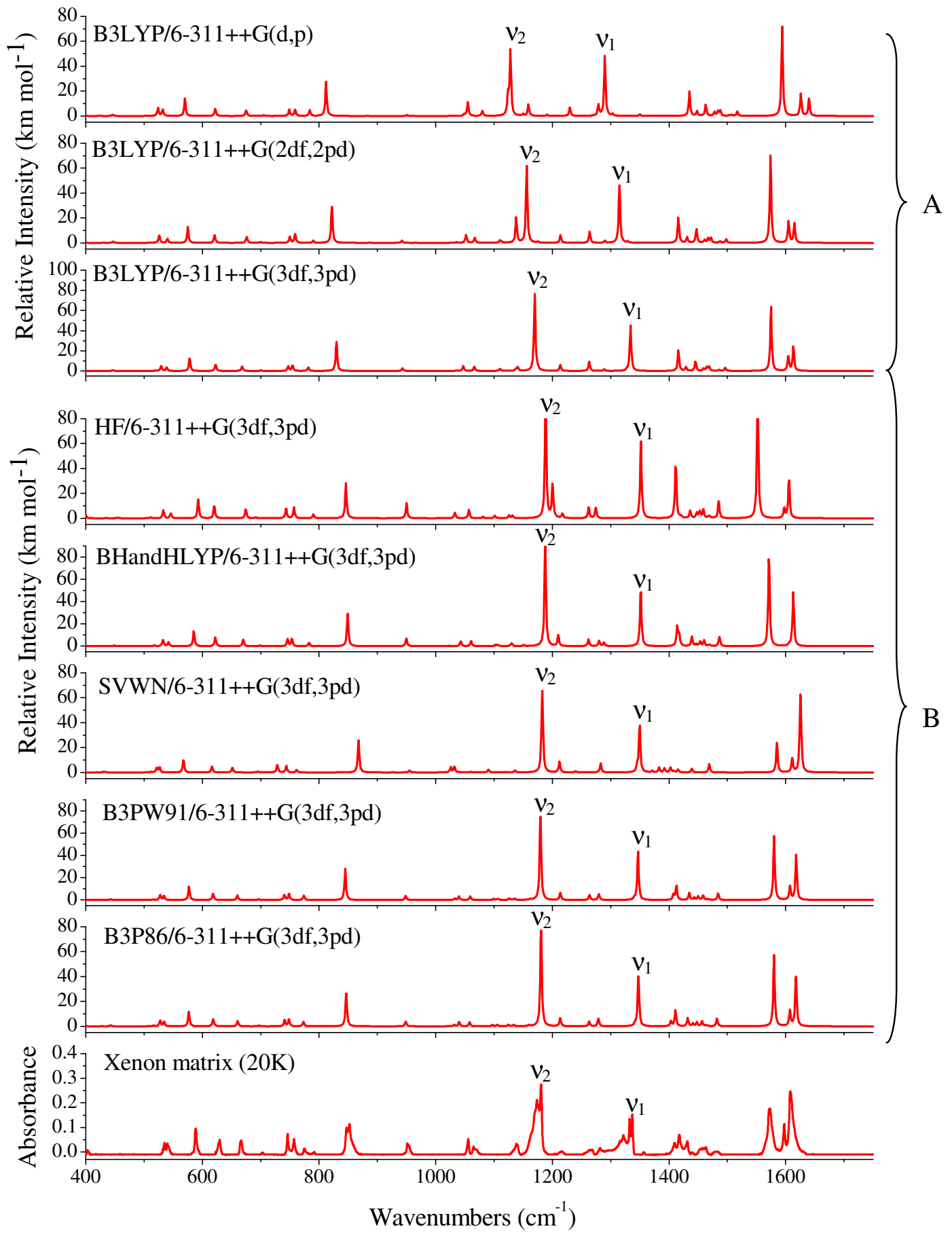

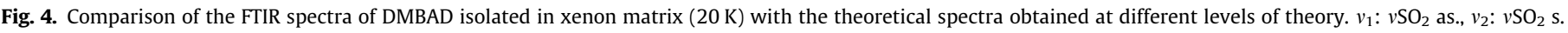
Group A depicts differences obtained with the use of polarization functions. Group B depicts differences observed using different basis sets.

\section{Conclusion}

The novel amino-substituted derivatives of saccharin, $\mathrm{N}$ methyl-1,2-benzisothiazol-3-amine 1,1-dioxide (MBAD) and $\mathrm{N}, \mathrm{N}$ dimethyl-1,2-benzisothiazol-3-amine 1,1-dioxide (DMBAD) were synthesized and characterized both structurally and vibrationally with the aid of matrix isolation spectroscopy and quantum chemical calculations. Among an extensive set of methods/basis set combinations tested, DFT(B3P86)/6-311++G(3df,3pd) and DFT(B3PW91)/6-311++G(3df,3pd) calculations emerged as the best ones to study these aminobenzisothiazol systems, where the pres- ence of the hypervalent sulphur atom imposes special care in choosing the level of theory to be applied. In particular, the B3P86 and B3PW91 functionals were found to perform somewhat better than the B3LYP functional (with the same basis set).

MBAD was shown to have two conformers: the most stable and sole form significantly populated in gas phase at room temperature, conformer A $\left(\mathrm{N}_{8}=\mathrm{C}_{9}-\mathrm{N}_{20}-\mathrm{H}_{21}: 180^{\circ}\right)$, and conformer B $\left(\mathrm{N}_{8}=\mathrm{C}_{9}-\mathrm{N}_{20}-\mathrm{H}_{21}: 0^{\circ}\right)$, ca. $20 \mathrm{~kJ} \mathrm{~mol}^{-1}$ higher in energy than the conformational ground state. This result was interpreted taking into account the more favorable interactions between the methylamino group and the benzisothiazol moiety [in particular $\mathrm{N}(8)$ and 
Table 3

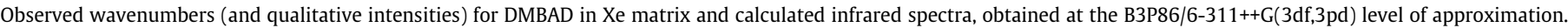

\begin{tabular}{|c|c|c|c|c|}
\hline \multirow[t]{2}{*}{ Approximate description $^{a}$} & \multicolumn{2}{|c|}{ Calculated $^{\mathrm{b}}$ B3P86/6-311++G(3df,3pd) } & \multicolumn{2}{|l|}{ Xenon $^{\mathrm{c}}(20 \mathrm{~K})$} \\
\hline & $v\left(\mathrm{~cm}^{-1}\right)$ & $I\left(\mathrm{~km} \mathrm{~mol}^{-1}\right)$ & $v\left(\mathrm{~cm}^{-1}\right)$ & $I$ (qualitative) \\
\hline$\delta \mathrm{C}-\mathrm{N}-\mathrm{C}_{\mathrm{M}}, \delta_{5 \mathrm{R}}$ & 516 & 2.4 & n.obs. & \\
\hline$\delta \mathrm{SO}_{2}, \delta \mathrm{C}-\mathrm{C}-\mathrm{C}_{6 \mathrm{R}} ; \delta_{5 \mathrm{R}}$ & 528 & 23.1 & $532 / 535$ & $\mathrm{w} / \mathrm{m}$ \\
\hline$\tau_{6 \mathrm{R}}$ & 534 & 17.0 & 539 & $\mathrm{~m}$ \\
\hline$\delta_{5 \mathrm{R}}, \gamma \mathrm{CO}_{2}$ & 577 & 56.6 & 588 & $\mathrm{~S}$ \\
\hline$\delta \mathrm{C}-\mathrm{C}-\mathrm{C}_{6 \mathrm{R}}, \delta_{5 \mathrm{R}}$ & 619 & 29.1 & $623 / 628 / 630$ & $\mathrm{w} / \mathrm{m} / \mathrm{m}$ \\
\hline$\tau_{6 \mathrm{R}}, \delta_{5 \mathrm{R}}$ & 660 & 21.2 & $664 / 666$ & $\mathrm{~m} / \mathrm{m}$ \\
\hline$\delta \mathrm{C}-\mathrm{C}-\mathrm{C}_{6 \mathrm{R}}, v \mathrm{C}-\mathrm{S}$ & 697 & 3.7 & 703 & w \\
\hline$\delta \mathrm{C}-\mathrm{C}-\mathrm{C}_{6 \mathrm{R}}, \tau_{6 \mathrm{R}}$ & 741 & 24.1 & 746 & $\mathrm{~m}$ \\
\hline$\gamma \mathrm{C}-\mathrm{H}_{6 \mathrm{R}}, \tau_{6 \mathrm{R}}$ & 748 & 27.7 & 757 & $\mathrm{~m}$ \\
\hline$\delta \mathrm{N}-\mathrm{C}-\mathrm{N}, \gamma \mathrm{C}-\mathrm{H}_{6 \mathrm{R}}, \tau_{6 \mathrm{R}}$ & 773 & 17.5 & 775 & w \\
\hline$v \mathrm{~N}-\mathrm{S}, v \mathrm{~N}-\mathrm{C}_{\mathrm{M}}$ & 847 & 133.2 & $847 / 850 / 853$ & $\mathrm{~S} / \mathrm{S} / \mathrm{S}$ \\
\hline$\gamma \mathrm{C}-\mathrm{H}_{6 \mathrm{R}}$ & 874 & 0.5 & 872 & vw \\
\hline$v \mathrm{~N}-\mathrm{S}, v \mathrm{~N}-\mathrm{C}_{\mathrm{M}}, \delta \mathrm{N}-\mathrm{C}-\mathrm{N}$ & 949 & 18.3 & $952 / 953$ & $\mathrm{~m} / \mathrm{m}$ \\
\hline$\gamma \mathrm{C}-\mathrm{H}_{6 \mathrm{R}}$ & 952 & 0.4 & n.obs. & \\
\hline$\gamma \mathrm{C}-\mathrm{H}_{6 \mathrm{R}}$ & 988 & 0.0 & n.obs. & \\
\hline$v \mathrm{C}-\mathrm{C}_{6 \mathrm{R}}$ & 1032 & 5.7 & n.obs. & \\
\hline$\delta \mathrm{C}-\mathrm{C}-\mathrm{C}_{6 \mathrm{R}}$ & 1040 & 16.8 & 1056 & $\mathrm{~m}$ \\
\hline$\gamma \mathrm{CH}_{3}, v \mathrm{~N}-\mathrm{C}_{\mathrm{M}}$ & 1058 & 15.2 & $1065 / 1069$ & $\mathrm{~m} / \mathrm{m}$ \\
\hline$\gamma \mathrm{CH}_{3}$ & 1097 & 5.4 & n.obs. & \\
\hline$\gamma \mathrm{CH}_{3}, v \mathrm{C}-\mathrm{C}_{6 \mathrm{R}}$ & 1106 & 5.6 & 1112 & w \\
\hline$\gamma \mathrm{CH}_{3}$ & 1125 & 6.5 & 1133 & $\mathrm{~m}$ \\
\hline$\delta \mathrm{C}-\mathrm{H}_{6 \mathrm{R}}, v \mathrm{C}-\mathrm{C}_{6 \mathrm{R}}$ & 1134 & 5.8 & 1139 & $\mathrm{~m}$ \\
\hline$\delta \mathrm{C}-\mathrm{H}_{6 \mathrm{R}}$ & 1160 & 4.3 & 1161 & $\mathrm{~m}$ \\
\hline$v \mathrm{SO}_{2} \mathrm{~S}$ & 1181 & 384.8 & $1165 / 1170 / 1174 / 1181$ & $\mathrm{~m} / \mathrm{S} / \mathrm{VS} / \mathrm{VS}$ \\
\hline$v \mathrm{C}-\mathrm{C}_{6 \mathrm{R}}, v \mathrm{~N}-\mathrm{C}_{\mathrm{M}}$ & 1214 & 32.6 & 1215 & $\mathrm{~m}$ \\
\hline$\delta \mathrm{C}-\mathrm{H}_{6 \mathrm{R}}$ & 1263 & 18.3 & 1265 & w \\
\hline$v \mathrm{C}-\mathrm{C}_{5 \mathrm{R}}$ & 1279 & 29.7 & 1282 & w \\
\hline$\delta \mathrm{C}-\mathrm{H}_{6 \mathrm{R}}$ & 1342 & 6.9 & $1315 / 1321$ & $\mathrm{~m} / \mathrm{m}$ \\
\hline$v \mathrm{SO}_{2}$ as & 1347 & 209.2 & $1332 / 1337 / 1355$ & $\mathrm{VS} / \mathrm{VS} / \mathrm{w}$ \\
\hline$\delta \mathrm{CH}_{3} \mathrm{~S}$ & 1403 & 19.2 & 1409 & $\mathrm{~m}$ \\
\hline$\delta \mathrm{CH}_{3} \mathrm{~S}$ & 1411 & 61.4 & 1418 & $\mathrm{~m}$ \\
\hline$v \mathrm{C}-\mathrm{N}$ & 1432 & 30.7 & 1432 & $\mathrm{~m}$ \\
\hline$\delta \mathrm{C}-\mathrm{H}_{6 \mathrm{R}}$ & 1441 & 10.9 & 1439 & w \\
\hline$\delta \mathrm{CH}_{3}$ as & 1448 & 16.0 & 1454 & $\mathrm{~m}$ \\
\hline$\delta \mathrm{C}-\mathrm{H}_{6 \mathrm{R}}$ & 1457 & 20.1 & 1457 & $\mathrm{~m}$ \\
\hline$\delta \mathrm{CH}_{3}$ as & 1463 & 3.1 & 1463 & $\mathrm{~m}$ \\
\hline$\delta \mathrm{CH}_{3}$ as & 1466 & 1.8 & n.obs. & \\
\hline$\delta \mathrm{CH}_{3}$ as & 1482 & 30.1 & 1480 & w \\
\hline$v \mathrm{C}=\mathrm{N} ; v \mathrm{C}=\mathrm{C}_{6 \mathrm{R}}$ & 1580 & 270.1 & 1573 & VS \\
\hline$v \mathrm{C}=\mathrm{C}_{6 \mathrm{R}}$ & 1607 & 60.9 & 1598 & $S$ \\
\hline$v \mathrm{C}=\mathrm{N}_{5 \mathrm{R}}, v \mathrm{C}=\mathrm{C}_{6 \mathrm{R}}$ & 1618 & 202.2 & 1608 & VS \\
\hline
\end{tabular}

${ }^{a} v$, bond stretching; $\delta$, bending; $\gamma$, rocking; $\tau$, torsion; s, symmetric; as, anti-symmetric; subscripts $6 \mathrm{R}$, 5R and M designate the six- and the five-membered rings and the methyl group, respectively.

b Wavenumbers were scaled by 0.9763 .

c S, strong; VS, very strong; m, medium; w, weak; vw, very weak; sh, shoulder; n. obs., non observed; n.a., non-analyzed.

$\mathrm{H}(10)]$ in conformer $\mathbf{A}$ than in conformer B. In both MBAD conformers, the amino group is predicted to be non-pyramidalized, the $\mathrm{C}(9)-\mathrm{N}(20)$ bond being appreciably shorter than the equivalent bond in DMBAD, where the amino group is pyramidal. Along the pathway for conformational interconversion in MBAD, the amino group was also predicted to be pyramidalized, in particular at the transition state, which has an energy of $\sim 90 \mathrm{~kJ} \mathrm{~mol}^{-1}$ higher than conformer A. This high energy barrier reinforces the conclusion that the $\mathrm{C}(9)-\mathrm{N}(20)$ bond in MBAD has a substantial partial double bound character.

The different structural preferences about the amine nitrogen atom in the two molecules were explained in terms of repulsive interactions involving the additional methyl group of DMBAD [specifically, $\mathrm{CH}_{3} \ldots \mathrm{H}(10)$ repulsions]. The differences in geometry and bond lengths are in agreement with results obtained concerning the relative reactivity of both compounds towards nucleophilic substitution at $\mathrm{C}(9)$, with DMBAD being much more reactive than MBAD.

The matrix isolated spectra obtained for both compounds could be predicted very accurately by the B3P86/6-311++G(3df,3pd) calculations performed on their corresponding most stable conformations. This fact allowed easy full spectral assignment to be done for both compounds and appears as a strong additional support to the characterization of the structures theoretically predicted for the two molecules investigated.

\section{Acknowledgements}

We acknowledge the "Cyfronet" Computer Center, Krakow (Grant KBN/SGI/ORIGIN_2000/UJ/ 044/1999), the Portuguese Science Foundation (Project PTDC/QUI/71203/2006 and PTDC/QUI/ 67674/2006), the Argentinean Agencia Nacional de Promoción Científica y Tecnológica (Project PICT/2006/68), CYTED (Network P108RT0362). A.G.Z. is member of the research career CONICET (National Research Council, Argentina).

\section{Appendix A. Supplementary data}

Supplementary data associated with this article can be found, in the online version, at doi:10.1016/j.molstruc.2009.09.027.

\section{References}

[1] M. Mor, F. Zani, P. Mazza, C. Silva, F. Bordi, G. Morini, P.V. Plazzi, Farmaco 51 (1996) 493. 
[2] A.F. Brigas, R.A.W. Johnstone, Tetrahedron Lett. 31 (1990) 5789.

[3] N.C.P. Araújo, A.F. Brigas, M.L.S. Cristiano, L.M.T. Frija, E.M.O. Guimarães, R.M.S. Loureiro, J. Mol. Catal. A: Chem. 215 (2004) 113.

[4] L.M.T. Frija, M.L.S. Cristiano, E.M.O. Guimarães, N.C. Martins, R.M.S. Loureiro, J.F. Bickley, J. Mol. Catal. A: Chem. 242 (2005) 241 (and references therein).

[5] A.F. Brigas, R.A.W. Johnstone, J. Chem. Soc. Chem. Commun. (1994) 1923.

[6] J.V. Barkley, M.L.S. Cristiano, R.A.W. Johnstone, R.M.S. Loureiro, Acta Crystallogr. C: Cryst. Struct. Commun. 53 (1997) 383

[7] M.L.S. Cristiano, A.F. Brigas, R.A.W. Johnstone, R.M.S. Loureiro, P.C.A. Pena, J. Chem. Res. (S) (1999) 704.

[8] N.C.P. Araújo, P.M.M. Barroca, J.F. Bickley, A.F. Brigas, M.L.S. Cristiano, R.A.W. Johnstone R.M.S. Loureiro, P.C.A. Pena J. Chem. Soc. Perkin Trans. 1 (2002) 1213.

[9] R. Almeida, A. Gómez-Zavaglia, A. Kaczor, M.L.S. Cristiano, M.E.S. Eusébio, T.M.R. Maria, R. Fausto, Tetrahedron 64 (2008) 3296.

[10] A. Gómez-Zavaglia, A. Kaczor, R. Almeida, M.L.S. Cristiano, M.E.S. Eusébio, T.M.R. Maria, P. Mobili, R. Fausto, J. Phys. Chem. A 113 (2009) 3517.

[11] A. Gómez-Zavaglia, A. Kaczor, D. Coelho, M.L.S. Cristiano, R. Fausto, J. Mol. Struct. 919 (2009) 271.

[12] A. Gómez-Zavaglia, A. Kaczor, R. Almeida, M.L.S. Cristiano, R. Fausto, J. Phys. Chem. A 112 (2008) 1762.

[13] A. Kaczor, R. Almeida, A. Gómez-Zavaglia, M.L.S. Cristiano, R. Fausto, J. Mol. Struct. 876 (2008) 77.

[14] A. Kaczor, L.M. Proniewicz, R. Almeida, A. Gómez-Zavaglia, M.L.S. Cristiano, A.M. Matos Beja, M. Ramos Silva, R. Fausto, J. Mol. Struct. 892 (2008) 343.

[15] A.H. Zeng, L. Yu, Y. Wang, Q.Y. Kong, Q. Xu, M.F. Zhou, J. Phys. Chem. A 108 (2004) 6656.

[16] A. Borba, A. Gómez-Zavaglia, P.N.N.L. Simões, R. Fausto, Spectrochim. Acta A 61 (2005) 1461
[17] A. Borba, A. Gómez-Zavaglia, P.N.N.L. Simões, R. Fausto, J. Phys. Chem. A 109 (2005) 3578.

[18] D.R. Lide (Ed.), Handbook of Chemistry and Physics, 74th ed., CRC Press, Boca Raton, 1993. pp. 9-123.

[19] S.W. McCombie, in: B. Trost, I. Fleming (Eds.), Comprehensive Organic Synthesis, vol. 8, Pergamon Press, Oxford, pp. 826-828 (Chapter 4.2).

[20] M.J. Frisch, G.W. Trucks, H.B. Schlegel, G.E. Scuseria, M.A. Robb, J.R. Cheeseman, J.A. Montgomery Jr., T. Vreven, K.N. Kudin, J.C. Burant, J.M. Millam, S.S. Iyengar, J. Tomasi, V. Barone, B. Mennucci, M. Cossi, G. Scalmani, N. Rega, G.A. Petersson, H. Nakatsuji, M. Hada, M. Ehara, K. Toyota, R. Fukuda, J. Hasegawa, M. Ishida, T. Nakajima, Y. Honda, O. Kitao, H. Nakai, M. Klene, X. Li, J.E. Knox, H.P. Hratchian, J.B. Cross, V. Bakken, C. Adamo, J. Jaramillo, R. Gomperts, R.E. Stratmann, O. Yazyev, A.J. Austin, R. Cammi, C. Pomelli, J.W. Ochterski, P.Y. Ayala, K. Morokuma, G.A. Voth, P. Salvador, J.J. Dannenberg, V.G. Zakrzewski, S. Dapprich, A.D. Daniels, M.C. Strain, O. Farkas, D.K. Malick, A.D. Rabuck, K. Raghavachari, J.B. Foresman, J.V. Ortiz, Q. Cui, A.G. Baboul, S. Clifford, J. Cioslowski, B.B. Stefanov, G. Liu, A. Liashenko, P. Piskorz, I. Komaromi, R.L. Martin, D.J. Fox, T. Keith, M.A. Al-Laham, C.Y. Peng, A. Nanayakkara, M. Challacombe, P.M.W. Gill, B. Johnson, W. Chen, M.W. Wong, C. González, J.A. Pople, GAUSSIAN 03, Revision C.02, Gaussian, Inc., Wallingford, CT, 2004.

[21] P. Csaszar, P. Pulay, J. Mol. Struct. 114 (1984) 31.

[22] O. Farkas, H.B. Schlegel, J. Chem. Phys. 111 (1999) 10806.

[23] P. Pulay, G. Fogarasi, F. Pang, J.E. Boggs, J. Am. Chem. Soc. 101 (1979) 2550.

[24] J.M.L. Martin, C. Van Alsenoy, GAR2PED, University of Antwerp, 1995.

[25] A.F. Brigas, W. Clegg, C.J. Dillon, C.F.C. Fonseca, R.A.W. Johnstone, J. Chem. Soc. Perkin 2 (2001) 1315. 